\title{
Counter transference as an active impediment among health professionals: A mini review
}

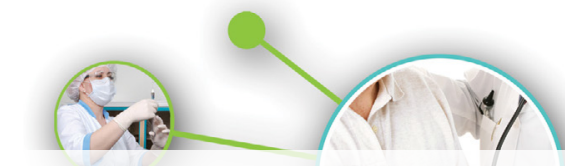

\begin{abstract}
It is a challenging task to work with traumatized clients, as they may present an exigent history. Post-traumatic stress disorder is one of the very common distress experienced by clients who have very recently undergone some major negative life changes in the form of death of a family member or close friend, faced a near to death experience, confronted an accidental sight. Their personal traumatic narratives are loaded with such difficult and throbbing accounts that can change their individuality and self, leading to psychological scars and injuries. To recover from such troubles and disturbances, clients might need therapies to compensate for the traumatic event. In this process, health professionals are at a higher risk of developing complex counter transference reactions (CTR's). In this review, we present the major challenges experienced by the health care professionals who are constantly involved with clients having a traumatic history including post-traumatic psychological disorder, natural disaster, death, and bereavement social upheaval, etc.
\end{abstract}

\section{Keywords: counter transference reactions (CTR's), post-traumatic stress disorder, trauma, empathy, client and health professional relationship}

\section{Introduction}

In any psychotherapeutic session, very strong emotional reactions might develop between the client and the health care professional. This is what has been referred to as transference and counter transference reactions in the literature. Health care professionals are prone to many serious and undesirable consequences like vicarious traumatization, secondary traumatic stress traumatic counter transference burnout and compassion fatigue, while working with traumatized clients [1]. Transference reactions can be defined as a negative or positive reaction towards a therapist by a client. Negative reactions would include behaviors like disappointment anger and frustration and positive emotions would include love, excessive ideation praise, etc. Similarly, counter transference issues are the conscious or unconscious emotional reactions that arise during a session between the client who is undergoing severe mental trauma or unresolved conflicts and the health care professional [2]. Trauma, as defined by the American Psychiatric Association (2000), is an exposure to a situation in which a person is confronted with an event that involves actual or threatened death or serious injury or threat to self or others physical well- being. There can be multiple reactions resulting from these traumas like intense fear, helplessness, and disgust, etc. The after effects of these traumas can precipitate in the form of severe anxiety or arousal not present prior to the traumatic event. This review explores the potential to affect health care professionals while interacting with seriously traumatized clients.

The concept of counter transference has been borrowed from Freud's theory of Psychoanalysis [3]. Transference has been defined as a process of bringing the conflicts of the client's past into the present; by mitigating it with the therapist. Freud has analyzed the phenomenon of transference in which he has stated the therapist to notice the distortions and vagueness in the client's perception of reality [4]. The responses of the health care professional can induce various reactions in the client. This process has been viewed as a course of interaction between the health care professional and the client during a therapeutic alliance. Further, Freud has viewed counter transference as a dangerous thing that can dilute the genuinity of a therapeutic relationship between the client and the health care professional. Under the phenomenon of

\section{Dwivedi Ramya*}

Department of Psychology, IILM University, Gurgaon, Haryana, India

*Author for correspondence:

ramyadwivedi@rediffmail.com 
counter transference, the health care professional develops a strong emotional feeling towards the client which is not permissible because he has to take up the role of a neutral and objective individual keeping oneself detached with all the emotional turmoil and issues of the client. Rackers has defined counter transference as something which arises out of the health care professional identifying oneself with clients internal feelings or emotions. According to Racker [5], these responses from the side of a health care professional can initially be repressed or blocked but later would definitely reach the surface level and affect the therapeutic alliance negatively.

Effects of counter transference reactions: Counter transference if not handled carefully can lead to distortions in the client's perceptions and can mislead the treatment as well. Broadly, counter transference has been defined as the totality of emotions that the health care worker feels towards the client. Counter transference can have a serious negative impact on the clientcounselor relationship and rapport building. Treatment outcome of the client depends upon the quality of the therapeutic relationship between the client and health care professional. Some of the possible reasons for the counter transference effects are inflexibility, being annoyed with the therapist or clinician; opposing advice, etc. They need to train themselves in order to manage counter transference issues effectively especially the ones related to displace reactions stemming from past experiences of the therapist or clinician. The paramedics have been reported to such critical events that may impede their mental health and elevate their levels of stress and anxiety. During any traumatic event, the paramedics tend to develop a strong emotional connect with the victims, making them more prone to emotional empathy thus shifting them beyond the cognitive understanding. Studies have explored that such population is more prone to post-traumatic stress disorder [6]. Other studies conducted with the firefighters have revealed that they experience increased psychological distress due to their identification with the victims of disaster [7]. Health care professionals lessen experiences of negative counter transference. Counter transference interferes with understanding and provoking behavior that meets the therapists' needs rather than the patients.

The therapists counter transference reactions can influence the different phases of therapy like patient's resistance, depth of elaboration and even the therapeutic alliance. A lot many times emotional responses/reactions of the health care professional is laden with information about the client's personality. A number of approaches have been proposed in the context of transference and counter transference. We are mentioning about two major approaches viz. classic and totalistic that operates during transference or counter transference. Starting with the classic approach that tends to stimulate the health care professionals childhood based unresolved conflicts because of the patient's transference needs to be carefully addressed and managed. The health care professional keeps reflecting the clients interpersonal functioning partially under the totalistic perspective [8].

\section{Role of Empathy in Counter Transference}

Empathy as an essential prerequisite during a counseling session, if not handled carefully can be one of the prime impediment in the smooth conduction of the sessions between the client and health care professional leading to transference or counter transference. Carl Rogers was the prime proponent of empathy. He defined empathy as the ability to perceive the internal frame of reference of another person accurately "as if" we are that person by understanding the perspective of the other person but at the same time keeping oneself aloof and not losing oneself with the "as if" condition. Literature review states that there are two aspects of counter transference viz. the counter transference reaction and empathic understanding. Counter transference is the conscious response of the health professional in a session with a client. The material emerges from the preconscious level of the client by virtue of their current transference. Empathy, on the other hand, is a perspective whereby the health care professional puts up an effort to understand and analyze the current state of the client in order to understand the perspective and concerns [9]. It is defined as the ability to understand someone else's feelings and situations through their lens or perspective. Empathy would include both transference and counter transference issues that arise during a therapeutic alliance. This allows for a deep rapport formation that cultivates authenticity and genuineness between the client and health care professional. Pavio and Laurent have elucidated empathy something to be accurately communicated by the client to the health care provider. It should give a lucid picture of the client's prime issues concerns and 
goals [10]. Empathy should be communicated in such a way that the health care provider can relate to the client without getting affected emotionally i.e. to say keeping oneself neutral towards the issues and concerns of the client.

Counter transference can be monitored by the health care professional if she develops an understanding within him and works successfully with the inevitable conflictual feelings experienced by the health professional towards the client during the therapeutic alliance so as to enhance the therapeutic progress. A health care professional should have the ability to empathize with the client keeping oneself neutral. Theory of psychoanalysis states that both empathy and counter transference feelings and behaviors result from identification with the client. Empathy building allows the health care professional to understand the experiences of the client. Counter transference basically emerges out of the irrational and conflictual internal reactions of the counselor, when the client's transference reactions touch the health professional/counselor.

Empathic feelings and counter transference behavior appear from identification with the client. Health professionals exhibit feelings of counter transference behavior under two situations [11-13] firstly, through over or underemphasizing the emotionally laden material that might be intimidating and secondly, a conscious decision of withdrawing oneself by not getting involved with the client's issue. This state might also lead to counter transference behaviors.

\section{Conclusion}

As defined earlier, counter transference refers to the emotional reactions and responses of the health care professional towards a client. These reactions might result from the counselor's personal life experience. Thus counter transference may be summarized as a phenomenon occurring during a therapeutic alliance. It is also considered to be an important tool in all therapy. For the effective and smooth progression of the therapy, the health professional must have a general awareness of both the transference and counter transference issues. If the therapist can effectively manage counter transference reactions during a therapy session, it plays a crucial role in the treatment of personality disorder. This knowledge would automatically help the health personnel to identify their own areas of emotional vulnerability and disturbances, thus making the process of therapeutic counseling easier accurate and genuine. Thus the aforesaid factors come out to be the possible disruptions to the therapeutic alliance that can negatively impact the client and health care worker relationship. 


\section{REFERENCES}

$S$ Collins, A Long. Working with the psychological effects of trauma: Consequences for mental health care workers-a literature review. J. Psychiatr. Nurs. Ment. 10(4), 417-424 (2003).

Jeffrey A Hayes. The inner world of the psychotherapist: A program of research on counter transference. Psychother. Res. 14(1), 21-36 (2004).

Christine Lynn Norton. Developing empathy: A case study exploring transference and counter transference with adolescent females who self injure. $J$. Social Work Practi. 25 (1), 95-107 (2011).

Cabaniss D, Cherry S, Douglas CJ, Schwartz AR. Psychodynamic psychotherapy: A clinical manual. (2011).

Racker H. The meaning and uses of countertransference', in Essential Papers on Countertransference, ed. B. Wolstein, New York University Press, New York, (1988).

Carlier I, Lamberts R, Gersons B. The dimensionality of trauma: A multidimensional comparison of police officers with and without posttraumatic stress disorder. Psychiatric Res. 97, 29-39 (2000).

Fullerton C, McCarroll J, Ursano R, Wright K. Psychological responses of rescue workers: Firefighters and trauma. Am. J. Orthopsychiatry. 62, 371-378 (1992).

Antonello Colli, Martina Ferri, "Patient personality and therapist counter transference". Curr. Opin. Psychiatry. 28(1), 46-56 (2015).

Zepf S, Hartmann S. Some thoughts on empathy and counter transference. $J$. Am. Psychoanal. Assoc. 56 (3), 741-768
(2008).

Pavio SC, Laurent C. Empathy and emotion regulation: Reprocessing memories of childhood abuse. J. Clin. Psychol. 57(2), 213-226 (2010).

Peabody, Shelley Ann. Counter transference and Empathy: The complex relationship between two divergent concepts in Counseling, Maryland University, College Park, Counseling Center. (1981).

"Therapeutic Issues for Counselors" Chapter-4, Book entitled, Treatment Improvement Protocol (TIP), Series No. 36, Centre for Substance Abuse Treatment. (2000).

Wachtel PL. Transference, schema, and assimilation: The relevance of piaget to the psychoanalytic Theory of transference. (1987). 